\title{
Postmortem procedures in the emergency department: using the recently dead to practise and teach
}

\author{
Kenneth V Iserson University of Arizona College of Medicine, Tucson, Arizona, USA
}

\section{Author's abstract \\ In generations past, it was common practice for doctors to learn lifesaving technical skills on patients who had recently died. But this practice has lately been criticised on religious, legal, and ethical grounds, and has fallen into disuse in many hospitals and emergency departments. This paper uses four questions to resolve whether doctors in emergency departments should practise and teach non-invasive and minimally invasive procedures on the newly dead:}

Is it ethically and legally permissible to practise and teach non-invasive and minimally invasive procedures on the newly dead emergency-department patient?

- What are the alternatives or possible consequences of not practising non-invasive and minimally invasive procedures on newly dead patients?

- Is consent from relatives required?

Should doctors in emergency departments allow or even encourage this use of newly dead patients?

Several factors suggest that postmortem practice and teaching is necessary: the importance of clinical competence when performing lifesaving procedures, society's need to maintain and expand the cadre of medical personnel with lifesaving skills, and the inadequacy of alternative teaching methods. Doctors are ethically compromised when, instead of doing postmortem practice, they either use patients in the operating room without consent or delay pronouncing death during resuscitations to practise and teach. Contrary to what is often claimed, there is neither a legal nor a moral basis for requiring relatives' consent for minimally invasive and non-invasive postmortem procedures. The obligations society has placed on emergency doctors dictate that they encourage the use of the recently dead for the practice and teaching of non-invasive and minimally invasive lifesaving procedures. The medical profession has a duty to openly acknowledge this need and to educate the public about it.

\section{Key words}

Emergency medical services; attitude to death; teaching; teaching materials; cadaver; education, medical.

\section{Introduction}

In generations past, it was common practice for doctors to learn technical skills, such as intubation, on patients who had recently died (1-5). Students and residents learned the mysteries of lifesaving procedures from experienced clinicians shortly after a patient's death, and experienced clinicians honed their skills on the recently dead in order to remain proficient. But lately this practice has been criticised on religious, legal, and ethical grounds, and so despite the potential adverse ramifications, it has fallen into disuse in many hospitals and emergency departments (EDs).

This decrease in doctors' use of corpses to enhance skills is especially troublesome in a time of increased need. It is obvious that experienced clinicians neither appear de novo nor remain experienced without practice. Until recently, doctors who worked in emergency care areas had little need for added practice in endotracheal intubation or central line placement, because the mere frequency of these critical care procedures produced competence. Now however, procedures such as endotracheal intubations are often performed in the field by highly trained ambulance personnel; only the most difficult procedures are left for the ED staff, who consequently may lose proficiency in their lifesaving skills (3). This expertise is a genuine value both to society in general and to all patients needing emergency care. Therefore, it is society's responsibility to encourage practitioners to develop lifesaving skills in a manner that will help patients, rather than harm them.

However, the medical profession's attention has been drawn to the religious, legal, and ethical arguments against the use of the newly dead for education. These arguments often clash with the scientific/medical view that during life, the body and personhood are integrally related, whereas after death the person is gone and only the body remains. The doctor/scientist could in no sense use the term 'person' to describe former patients who have not been successfully resuscitated, since they no longer interact with the environment or have any noticeable somatic activity. As Descartes implied, the ghost has departed the machine. 
All that remains is the body; the soul is gone. According to this view, while the body no longer signifies a human presence, it does command a certain respect as a reminder of that presence (6-8).

Nevertheless, in some religions what is done to and with the body after death is believed to affect the individual in an afterlife. For example, religious obligations were the basis for the burial ritual Antigone owed Polynices (9). As Carrick has pointed out, religious beliefs about death fall into four distinct groups: 1) death as a shadow, wandering through the underworld (Homeric/ Egyptian); 2) death as immortality of the soul (Plato/Christian); 3) death as immortality through offspring and fellow humans (Aristotle), and 4) death as the personal end of existence (Stoics/ Epicureans) (10).

No matter what the religious belief, the response to death has been horror (6), and in western society, death has become a shameful and forbidden subject (11). This may explain the reluctance of both clinicians and society fully to discuss the subject of this paper.

That it is now less common for doctors to practise and teach procedures on fresh cadavers may also be a result of our litigious society - a society that now questions what was discreetly but widely practised without comment in the past $(2,4,5)$. This reduced use of the newly dead may also be a result of the expansive and sometimes misapplied concept of autonomy in legal and ethical thought, and of the increased power of medical examiners who see their role as a major protector of the state's interest in criminal investigation.

The use of the newly dead for education raises ethical issues of deceit, consent, and nonmaleficence. Lifesaving medical procedures can be taught or practised either openly or by deceit and on the dead who can no longer be harmed or on the living who can be. 'Openly' implies that consent, actual or presumed, is required. Non-maleficence is based on the doctor's duty to have sufficient skills so as not to harm his or her patients.

Given these diverse attitudes towards death and the dead, questions arise over the permissibility of using a fresh corpse for training, the moral or legal rights of relatives, and the usefulness of other training methods. These questions will be discussed in relation to emergency doctors, who must decide whether it is permissible to practise noninvasive or minimally invasive procedures on the newly dead. The emergency doctor serves as a paradigm for all doctors, including most of those with hospital privileges, who must remain proficient in lifesaving procedures and who encounter newly dead patients with whom they have had little or no prior contact. First though, the terms 'dead' and 'non-invasive or minimally invasive procedures' should be clarified.
'Dead' patients can be divided into three ordered categories - each of which is ethically more problematic in regard to their use as subjects for clinical education or practice. These categories are: the clearly dead (cardiorespiratory death or death by brain criteria), the eerily dead (persistent vegetative state, sometimes called neocortical death), and the nearly dead (those about to die). This latter group is not dead by any legal or moral definition, and so must be clearly differentiated from the others. Whether the 'eerily dead' are dead from an ethical perspective is a subject of debate - they are definitely not legally dead. However, the 'clearly dead' are both ethically and legally dead, and are the only group in which invasive non-therapeutic teaching should take place in the ED. But while the clearly dead can be defined either by cessation of cardiorespiratory activity or by brain death criteria, brain death is not usually a substantive ED diagnosis. Therefore, the following discussion is limited to patients who have been declared dead by cardiorespiratory criteria. This group is both the least ethically problematic on which to practise and teach procedural skills and the one most applicable to emergency medicine.

In order to limit this discussion to lifesaving procedures that are non-mutilating, the terms 'noninvasive' and 'minimally invasive' should be defined. To teach or practise 'non-invasive' lifesaving medical procedures on the newly dead means to perform techniques which normally leave no mark on the body. Typically, this means intubation. The term 'minimally invasive' means those procedures that leave only isolated needle-marks, including central venous access, needle thoracostomy, pericardiocentesis, abdominal paracentesis, needle cricothyrotomy, percutaneous peritoneal lavage, or the application of cervical traction tongs (12).

If an argument is to be made that doctors in emergency departments should practise and teach on the newly dead, the following question must first be answered:

Is it ethically and legally permissible to practise and teach non-invasive and minimally invasive procedures on the newly dead ED patient?

Even if it is permissible, three more questions remain:

What are the alternatives to practising and teaching non-invasive and minimally invasive procedures on newly dead patients? What are the possible consequences of not doing it?

- Is consent from relatives required?

- Should doctors in EDs allow or even encourage this use of dead patients?

Each of these questions will be addressed in turn. 


\section{Ethical and legal considerations}

Is it ethically and legally permissible to practise and teach non-invasive and minimally invasive procedures on the newly dead ED patient?

Ethically, the question of whether it is permissible to train doctors, paramedics, and students through practice on newly dead bodies must be resolved by examining various competing interests. The strongest interest on one side is the need for realistic and readily available training in order to have a sufficient number of capable, clinically competent, and currently proficient ED and ambulance personnel, able to perform lifesaving procedures. Two strong competing interests are a need to respect the dead and the state's concern in being able to successfully investigate criminal wrongdoing.

Clinical competence to perform lifesaving procedures is recognised as the bedrock of emergency care. Since the 17 th century observers have recognised that 'the first mortal sin of a doctor is practising medicine without being thoroughly competent in the art' (13). As Jonsen says:

'Competence, in the sense of a disciplined understanding of the science and skilled manipulation of the art, has long been a medical virtue. If anything deserves the title "Hippocratic ethic", it is the imperative of competent practice of the art' (14).

Competence requires a mastery of both medical science and medical skills, and is itself a fundamental part of the ethics of medicine. It is 'the standard to which all doctors must be held - the goal of medical education and the expectation of the public' (14). If they fail to acquire and maintain lifesaving skills, emergency clinicians are deceiving the public by donning the mantle of healer without having acquired the substantive skills this implies.

Competence is especially important when clinicians perform invasive procedures, because of their substantial risk for complications (15). Both clinicians and clinical trainees are obligated to be competent to perform a procedure before they attempt it on patients who may be injured in the process $(2,12,16)$. This is most important in the emergency setting, where doctors often overestimate their abilities to perform lifesaving skills (17), but where patients expect to find competent clinicians when they are in need of lifesaving help.

Society then, has a need to maintain and expand the cadre of medical personnel with lifesaving skills. But this societal need competes with claims that to practise or teach procedures on the newly dead shows a lack of respect or overrides state interests. Consideration of these claims limits both what procedures can be done and which newly dead can be used.

\section{RESPECT FOR THE BODY}

One might argue that the interest in training doctors, although legitimate, is overriden by an interest in respecting the dead, and hence that postmortem practice and teaching on the newly dead should not be permitted. However, this practice does not denigrate the dead, but rather respects the real values that the dead body represents. Consequently, even though respect for the dead is a legitimate interest, it does not override the societal interest for clinician competence in allowing this practice.

Practising on the newly dead is not disrespectful, and actually disfigures a body far less than many other postmortem procedures. One need only peruse a manual on embalming techniques or investigate other recent western burial practices to discover that an isolated needle puncture would barely be noticed in the face of the postmortem mutilation that bodies routinely undergo $(11,18)$. The most common postmortem procedure in the US is the deeply invasive and useless practice of embalming which has become widespread in the US since it was introduced in the nineteenth century (11).

Postmortem teaching on the newly dead is also not disrespectful because it is done in a dignified manner. The respect doctors have for the dead stems from a religion-based medical tradition. Clinicians' behaviour towards, and treatment of, the bodies of their former patients reflects this (8). This may best be seen at autopsy, the most disfiguring of all medical procedures, which is done in a hushed environment and with a reverence for the life which once occupied the body.

In fact, the postmortem practice and teaching of lifesaving procedures is a way of showing respect, because it promotes the real value that the dead body symbolises rather than the sanctity of the symbol for its own sake. A doctor who practises or teaches medical procedures on a corpse does not demonstrate a reduced respect for either the body or the person who once occupied the body. Rather, the clinician shows increased respect when, as a last medical rite, he or she improves practitioners' lifepreserving skills for the next patient in need. In this instance, the symbol is the body that represents the person who was not resuscitated; one interest this body represents is society's wish to receive lifesaving medical care. The symbol should not be allowed to obscure real societal interests or to justify their abandonment.

To insist that the symbol should be respected for its own sake may become hypocritical when it actually threatens what the symbol stands for. Protecting human remains from desecration is important. But as Feinberg has pointed out, while the body constitutes an important human symbol, there is a danger of protecting this 'symbol of humanity at the expense of the vital human interests of a real person.' (7). He goes on to say, 'in the more egregious cases, the cherished symbol is an emblem of the very class of interests that are harmed, so that there is a kind of hypocritical inconsistency in the sentimental behaviour' (7). 


\section{STATE INTERESTS}

Some may argue that to practise and teach on newly dead ED patients overrides relevant state interests. This is the view of some medical examiners in the US who refuse to allow ED personnel to practise any procedures on patients under their jurisdiction who have been declared dead (3). Medical examiners can control ED use of the newly dead when their jurisdiction extends to anyone who dies suddenly, unexpectedly, or violently, or without having seen a doctor within 48 hours - virtually all ED deaths. The medical examiners' rationale is that any postmortem manipulation of the body may hinder a potential medicolegal investigation.

The state does have an important interest in pursuing wrongful deaths, but most ED deaths do not warrant medicolegal investigation. Those few that do can be predicted on the basis of the nature of the patient's injuries or the circumstances surrounding the death. The medical examiners' expansive view of a state interest in determining the cause of death overrides a greater societal need to keep an optimal number of emergency personnel proficient in lifesaving procedures. Society has a moral interest in guaranteeing 'that well-trained professionals will be available to continue to provide for and care for its citizens' (19). The availability of competent practitioners requires proficiency - a situation that is thwarted by many US medical examiners.

\section{Alternative educational methods}

Are there suitable alternatives to the use of the newly dead to educate and enhance clinical lifesaving skills?

When sorting out whether the newly dead should be used to practise and teach, it is important to consider the alternative teaching methods available, and the implications of the alternative methods that are actually being used.

The question of alternative teaching methods can be dealt with quickly. Although animals, donated embalmed cadavers, and models are useful ways to learn or practise some aspects of critical care techniques, they are generally poor simulations of the critically ill patient. The use of animals is itself ethically problematic, aside from becoming logistically ever more difficult $(2,4,20)$. Donated, preserved cadavers are less realistic, more expensive, and through statute, normally available only in health professions' schools $(20,21)$. Even when available, they have proved inadequate for teaching endotracheal intubation or the placement of central venous lines (22). Models have been shown to have even less utility. Ambulance personnel trained only on manikins have had less success with emergency intubation than those trained on animals or live people (23).

Currently used alternatives to ED postmortem procedures compromise the morality of prac- titioners. Doctors commonly delay the pronouncement of death during resuscitation in order to teach or practise procedures. This is a deceitful and harmful hypocrisy. The deceit is in the pretence that the clinicians may still benefit the patient. The potential harm has many variations: 1) the dying process may be prolonged; 2) costs may be increased (there are no costs to the family for postmortem procedures), and 3) present trainees may become unable to distinguish the end of a 'real' resuscitation from training sessions, thus prolonging the agony of their future patients.

Another common alternative is to practise procedures, usually oral intubation, without consent on patients in the operating room. But to learn or practise procedures on the living is much more ethically problematic than the similar use of a corpse. This distinction is based on Kant's categorical imperative: that persons should always be respected as ends in themselves and never treated merely as means to others' ends (24). This principle cannot be applied to the dead; it is, however, vital when doctors use live patients to teach. If the alternative of using recently deceased patients exists, the use of either operating-room patients without their consent to teach intubation skills or of prolonged resuscitations to teach critical care procedures cannot be justified.

These situations can only be remedied when the medical profession openly acknowledges its need and responsibility to do postmortem procedures, as has happened in Maryland. The Maryland Institute for Emergency Medical Services, in protocols approved by the Board of Medical Examiners of Maryland, certifies ambulance personnel competent in intubations only after they perform 'six fresh cadaver intubations' under an emergency doctor's direction (4).

There are no suitable alternatives that are as effective as the use of the newly dead to teach and enhance clinicians' lifesaving skills. The public, at least implicitly, recognises this. It is the medical profession's responsibility to communicate this both within the profession and to society.

\section{Relatives' and patients' interests}

Is the consent of relatives required to practise and teach non-invasive and minimally invasive procedures on the newly dead? And would the public lose trust in the medical profession if such practice were widely known?

Relatives often claim rights to a dead patient's body and thereby determine whether postmortem procedures will occur. But these rights must be viewed in terms of actual legal claims, the appropriateness of relatives to consent for the dead, and the barriers to education that such a claim, if valid, might present. If these claim-rights are valid, why was there no public outcry when they were ignored? 
Most importantly, how are relatives' interests to be balanced against the presumed interests of the deceased patients?

A commonly claimed interest is the relatives' 'quasi-property rights' (6) regarding the corpse. It has been claimed that to practise or teach procedures without explicit permission disregards these limited legal rights, which are based on the relatives' duty to dispose of the body and on their emotional ties to the person who formerly occupied it. However, according to the Supreme Courts of Florida, Georgia, and Michigan, the next of kin have no constitutionally protected property right to a dead body. These courts have ruled that the rights that control the integrity of one's body end with death and cannot be claimed by the next of kin (25-27). These are the only superior US courts to have ruled on this matter, but the diversity of their jurisdictions suggests a legal pattern that may continue.

It is also claimed that relatives have a right to consent to postmortem procedures. But in truth, the consent process itself is used for relatively few medical procedures. Consent is obtained from patients for unusually dangerous or invasive procedures; relatives are asked for consent to harvest organs, to perform non-forensic autopsies, or to use a body as an anatomical cadaver. A requirement for permission in these cases stems from the nature of the procedures - massively invasive, or for the living, dangerous. The non-invasive or minimally invasive procedures being advocated here are neither. The President's Commission for the Study of Ethical Problems in Medicine and Biomedical and Behavioural Research recommended that 'specific consent from next of kin' be obtained only when clinicians go 'beyond the normal scope of teaching' (1). Therefore, it is inconsistent to extend a consent requirement to minimally invasive and non-invasive postmortem procedures.

Requiring this permission from distraught relatives would also raise a significant emotional barrier for clinicians (3). In a survey of medical personnel involved in organ harvesting, a dislike of 'adding to relatives' distress by asking permission for donation' was the single biggest barrier to organ procurement (28). This barrier is even less likely to be breached in the face of what is often a sudden and unexpected emergency department death, especially for the seemingly more trivial request to teach or practise procedures. Any barrier such as this to ED postmortem procedures is compounded by the stringent time limitations imposed by the onset of rigor mortis, by the rapid transport of the body to the morgue, and by the press of duties for the ED staff once a resuscitation attempt has ended. Requiring relatives' consent for these postmortem procedures will further decrease the number of clinical personnel trained in lifesaving procedures.

But if postmortem practice and teaching on the newly dead has gone on for years, why has there been no public outcry (29)? There has been no such outcry because both society and the medical profession are rational. While no reasonable person believes that experienced doctors come full-blown out of medical school or that the clinician's hands suddenly become and remain skilful without practice, a common human characteristic is a wilful ignorance of process, especially an unpleasant process, and a determined focus on results. So while relatives have an interest in the result, they usually prefer not to be present during resuscitations, autopsies, or even routine invasive medical procedures (for example intravenous (IV) placement) on their loved ones. Everyone is aware of what takes place; no one wants it explicated. All of us recognise the need for well-practised lifesaving skills and therefore agree to remain silent and to let this necessary activity continue discreetly.

It is acknowledged, though, that the public's thoughts on the matter of practising and teaching on the newly dead will be diverse, since we live in a pluralistic society. All of us are justifiably and appropriately concerned that the dead are treated with respect; such respect must be maintained. The procedures discussed in this paper though, will not result in either disrespect or disfigurement. Neither will the practice and teaching of these procedures on the newly dead body add to the distress or sorrow of relatives. Knowing that the practice may help other patients may, in fact, ameliorate their suffering, as occurs in cadaver organ donation.

The wishes of the former patient must also be addressed and obeyed. Most people are much more altruistic than is generally believed. Studies indicate a natural tendency towards altruism through donations of both replaceable and non-replaceable body parts $(30,31)$. However, relatives' consent has been shown to be significantly less altruistic than personal consent. Relatives are more likely to act conservatively, ie, to refuse permission for organ retrieval from relatives, even though they would voluntarily donate their own organs (30). If family members oppose a decision that the former patient could reasonably have been expected to make, it is probable that they thereby thwart the deceased's wishes.

The dead can exercise their autonomy only through the indirect and often ineffective instruments of an advance directive and a legal will. Most ED corpses have no known advance directives (32). Even so, only a legal will normally speaks to the disposition of the body - and that is of no use in the ED. This leaves many individuals who are motivated by 'a sense of altruism, wanting to be of help to others' (33) without a way to do so in death.

Unfortunately, in the emergency setting, the dead have no chance to act on their good wishes. Optimally, statutes could be enacted to make this presumed consent explicit. But in their absence, because patients are more likely than not to agree to respectful practice for the sake of others, their 
consent should be presumed, without regard to relatives' wishes. Neither a legal nor a moral basis for requiring relatives' consent for minimally invasive and non-invasive postmortem procedures exists. It is merely a perverse and potentially destructive extension of the concept of informed consent.

\section{Encouraging the practice}

Even if postmortem procedures are permissible, should doctors in emergency departments allow or even encourage them? To simplify the question, if we may, ought we?

This question should be considered from the perspective of the emergency doctor's responsibilities. The primary responsibility is to stand ready to intervene to preserve the life of anyone who presents to the ED. The emergency doctor's duty is to every patient, and his or her skills and abilities must be adequate to the task (3).

While the ED patient is always the first concern of the doctor, other responsibilities prevail as well. If a patient in extremis has received the best appropriate ED care but has nevertheless succumbed to illness or injury, the doctor's responsibility shifts to the next critical patient. At that point, the emergency doctor's focus may turn to the professional requirements of medical students, ambulance personnel, and residents, who will need lifesaving skills to care for other critical patients. These multiple responsibilities, based on an assumption of clinical expertise in lifesaving skills, lends weight to the position that emergency doctors should encourage the practice and teaching of these skills on the newly dead.

Finally, if this practice is to be encouraged, one must ask whether the use of ED corpses is equitable. Emergency care personnel are available to anyone who needs their lifesaving services. The dead former patient comes from the same population the ED personnel treat. Since they do not know who will, by chance, be the next one to need this help, the system is a uniquely equitable lottery.

\section{Conclusion}

This paper has argued that it is ethically and legally permissible to practise and teach minimally invasive and non-invasive lifesaving procedures on the newly dead. Current alternatives are not acceptable, either because they do not adequately meet educational needs or because they are themselves ethically problematic. Consent from relatives is neither morally nor legally necessary, and may in fact contravene the wishes of the dead former patient. The obligations society has placed on all doctors who must rapidly treat lifesaving emergencies dictates that they encourage the use of the recently dead for the practice and teaching of non-invasive and minimally invasive lifesaving procedures.

\section{Acknowledgements}

The author wishes gratefully to acknowledge Anne Dudley Goldblatt, JD, Mary Mahowald, PhD, Ulf Nilsson, PhD, and Mark Siegler, MD, who assisted by reviewing this manuscript.

Kenneth V Iserson, MD, MBA, FACEP, is Director of the Arizona Bioethics Program and Professor of Surgery in the Section of Emergency Medicine at the University of Arizona College of Medicine, Tucson, Arizona, USA.

\section{References}

(1) President's Commission for the Study of Ethical Problems in Medicine and Biomedical and Behavioural Research. Research involving the comatose and cadavers. In: Implementing human research regulations. Washington, DC: Government Printing Office, 1983: 39-41.

(2) Orlowski J P, Kanoti G A. The ethics of using newly dead patients for teaching and practising intubation techniques. New England journal of medicine 1988; 319, 7: 439-441.

(3) Iserson $\mathrm{K} \mathrm{V}$. Using a cadaver to practise and teach. Hastings Center report. 1986; 16, 3: 28-29.

(4) Crawford T. Intubation training seems mysterious. Physician executive. 1987; 13: 25-26.

(5) Morhaim D K, Atkins J M. Consultations. Annals of emergency medicine 1986; 15: 1504.

(6) May W. Attitudes toward the newly dead. Hastings Center studies 1973; 1, 1: 3-13.

(7) Feinberg J. The mistreatment of dead bodies. Hastings Center report 1985; 15: 31-37.

(8) Kass L R. Thinking about the body. Hastings Center report 1985; 15: 20-30.

(9) Sophocles. Antigone. Athens: 441 B C. New York: Penguin Books, 1984.

(10) Carrick P. Medical ethics in antiquity. Dordrecht, the Netherlands: D Reidel, 1985.

(11) Aries P. Western attitudes toward death. Baltimore: The Johns Hopkins University Press, 1974.

(12) Bratterbo G, Seim S H. Teaching and training of invasive procedures on cadavers. Lancet 1988; 2 (8619): 1078-1079.

(13) Ahasverius F. Medicus peccans. 1684, Nuremberg: 1684: 2; as quoted in Jonsen A R. The new medicine and the old ethics. Cambridge, Mass: Harvard University Press, 1990.

(14) Jonsen A R. Asklepios as intensivist. In: Jonsen A R, ed. The new medicine and the old ethics. Cambridge, Mass: Harvard University Press, 1990: 17-37.

(15) Schroeder S A, Martin K I, Strom B L. Frequency and morbidity of invasive procedures. Annals of internal medicine 1978; 128: 1809-1811.

(16) Iserson $\mathrm{K} \mathrm{V}$. The supervision of physicians in training: an educational and ethical dilemma. Medical teacher 1988; 10, 2: 195-201.

(17) Casey W F. Experience of medical students in cardiopulmonary resuscitation. Lancet 1983; 1 (8339): 1444-1445.

(18) Strub C G, Frederick L G. The principles and practice of embalming (3rd ed). Dallas, Texas: Lawrence G Frederick, 1965.

(19) Orlowski J P, Kanoti G A, Mehlman M J. The ethical dilemma of permitting the teaching and perfecting of 
resuscitation techniques on recently expired patients. Fournal of clinical ethics 1991; 1: 201-205.

(20) Nelson M S. Models for teaching emergency medicine skills. Annals of emergency medicine 1990; 19, 3: 333-335.

(21) Bratteb G, Wisborg T. Instruksjon og ving av akuttmedisinske prosedyrer pa nylig avdde. Tidsskrift for den Norske laegeforening 1990; 110: 1380-1381.

(22) Weaver M E, Kyrouac J P, Frank S, Rabiovich S. A cadaver workshop to teach medical procedures. Medical education 1986; 20: 407-409.

(23) Stewart R D, Paris P M, Pelton G H, Garretson D. Effect of varied training techniques on field endotracheal intubation success rates. Annals of emergency medicine 1984; 13: 1032-1036.

(24) Kant I. Fundamental principles of the metaphysics of morals (vol 42). Chicago: University of Chicago Press, 1989: 272.

(25) State of Florida v Powell, 497 So 2d 1188-1198, 1986.
(26) Georgia Lions Eye Bank, Inc v Lavant, 335 S E 2d 127-129, 1985.

(27) Tillman $v$ Detroit Receiving Hospital, $360 \mathrm{~N}$ W $2 \mathrm{~d}$ 275-279. (Mich app 1984).

(28) Wakeford R E, Stepney R. Obstacles to organ donation. British journal of surgery 1989; 76: 435439.

(29) But see, Culver C M. Using a cadaver to practise and teach. Hastings Center report. 1986; 16, 3: 29.

(30) Oswalt R M. A review of blood donor motivation and recruitment. Transfusion 1977; 17: 123-135.

(31) Spital A, Spital M. Living donation. Attitudes outside the transplant center. Archives of internal medicine 1988; 148: 1077-1080.

(32) Iserson K V. Foregoing prehospital care: should ambulance staff always resuscitate? fournal of medical ethics 1991 ; 17: 19-24.

(33) Coller B S. The newly dead as research subjects. Clinical research 1989; 37, 3: 487-494. 